LA-8680-MS

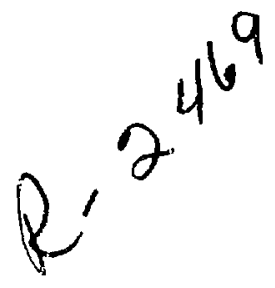

Comments on the Critical Issues for a High-Density Gas-Embedded Z-Pinch CTR Reactor Concept

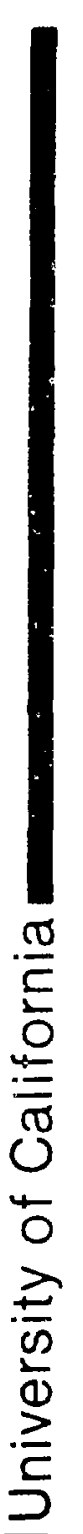


COMMENTS ON THE CRITICAL ISSUES FOR A

HIGH-DENSITY GAS-EMBEDDED Z-PINCH CTR REACTOR CONCEPT

by

Carl A. Ekdahl

\begin{abstract}
The issues considered critical for the realization of a Cr... reactor are discussed for the high-density gas-embedded $z$-pint:h cancept. A simple model of the pinch reactor is presented that gives estimates for $Q$ in substantial agreement with elaborate computer studies. An attempt is made to identify such critical points that are amenable to exploratory experiments. There appears to be no "fatal flaw" in the issues covered that would preclude a viable reactor based on this concept.
\end{abstract}

\title{
I. IN'TRODUCTION
}

The high-denstty, gas-embedded z-pinch (HDZP) has many advantages as an: advanced fusion reactoi concept, and there have been several reactor studies based on HoZP systems.1-3 These detalled studies used computer codes $L$, investigate the economics and feasibility of HDZP reactor systems. It is possible, however, co make estimates and scaling arguments for these conceptual reactor systems based on a simple heuristic model of the gas-embedded equilibrium pinch (see Appendix). The results of these estimates are in substantial agreement with the computer studies, but the simple model has the advantage that the physics is more reddily apparent.

The issues considered critical for the realization of a viable CTR reactor are briefly discussed in turn in this paper. Where required, estimates relating to heating, size, and economics will be made based on the simple heuristic model, if possible, in an attempt to clarify the physical processes 
involved. An attempt is also made to 1dentify those critical points amenable to exploratory experiments in the near future.

\section{I . CONF INEMENT CONF IGURATION}

\section{A. Equilibrium and Stab111ty}

The linear pinch is one of the simplest and most easily generated examples of a plasma equilibrium. However, the configuration is grossly unstable to MHD modes, 4,5 and successive efforts to control these have led to a class of toroldal devices with high magnetic shear (reversed-field pinches) that show promise as candidates for ohmically-heated reactors. The gas-embedded high-density $z$-plnch proposed here apfears to offer an attractfve alternative mears of controlling the MHD instabilities in a smaller device with higher energy density by relying on the inertia of the surrounding gas to slow the growth rate of the dangerous modes. There have been a number of experiments performed with results indicating that this approach to controlling MHD Instabllities may indeed provide the necessary time to achleve a batch burn of fuel if the retardation of growth rates can be extrapolated to the reactor regime of operation. In a recent study, Hartman, et al., ${ }^{2}$ assume that the growth rates can be sufficlently retarded, and conclude that a high-Q reactor with low output power is feastble. Hamme $\mathrm{l}^{1}$ and others ${ }^{3}$ at Los $\mathrm{Alamos}$ have independently reached the same conclusion.

\section{B. Enrrgy Losses}

An acceptable energy loss time can be calculated by assuming, as did Hammel, $l$ that losses are only by bremsstrahlung radiation. Including classical radial ion thermal losses to the problem results in some uncertainty as to the success of the reactor. There have been some theoretical results suggesting that this problem may not be serious (Ref. 4), ${ }^{\star}$ but $1 t$ is a concern, and can be invest igated in exploratory experfments.

*This information was supplied by T. Oliphant, August 1979. 
The neglect of axial losses is justifled in regions of large $\omega \tau$ because then classical transport w1ll be attenuated by $(\omega \tau)^{-2}$, and even if the transport is turbulent (Bohm-11ke) 1t should be attenuated by $(\omega \tau)^{-1}$. The thermal energy loss time to the ends is the $r \ell^{2} / v_{\text {tl. }} e^{\lambda}$ ee $\sim 2.7 \times 10^{-22} \mathrm{nl}^{2} / \mathrm{T}^{5 / 2} \mu \mathrm{s}$ in the absence of magnetic field. For $\mathrm{n}=10^{21} \mathrm{~cm}^{-3}$ and $T=10 \mathrm{keV}$, the resultant loss time is $\tau$ the $\sim 10^{-3} \ell^{2} \mu \mathrm{s}$, which is longer than the Lawson time for a pirch length, $\ell$, greater than $10 \mathrm{~cm}$. As a consequence, a short $10-\mathrm{cm}$ reactor would only require $\omega \tau=40$ for a $40 \times \tau_{\mathrm{L}}$ burn time and Bohm-l1ke transport energy losses. In the HDZP with 1.1-MA current this value of $\omega t$ is exceeded over virtually the entfre area, and axial losses can occur only in a very small region near the pinch axis.

However, even if significant axial losses were present a viable reactor would be possible. This was shown by Hartman, who Investigated the worst case, which is that of axtal free-streaming losses, in his study. ${ }^{3}$

\section{Divertor}

One of the distinct advantages of a HDZP reactor is the lack of divertor or high vacuum problems. The DT fuel gas will be at a few atmospheres pressure, and will isolate the pinch from materlal evaporated from the walls during the burn cycle.

\section{HEATING METHOD}

The proposed method of heating the HDZP is classical ohmic heating. This predominantly heats the olasma electrons, which then must transfer their energy to the lons. In most laboratory plasmas, the equilibration of energy between electrons and lons is a slow process, and because $1 t$ is implicit in the governing equations for the HDZP that the lons and electrons are at all times at the same temperature, the validity range for this assumption should be examined. Comparison of the ohmic heating rate with the rate of energy transfer to lons shows that the condition for the equilibration to be faster than the heating is $\mathrm{N}_{\ell}>10^{16} \mathrm{~cm}^{-1}$. Furthermore, comparing the equilibration rate with the rate of energy loss from bremsstrahlung radiation yields the condition on the electron temperature for equilibration to be faster; $\mathrm{T}_{\mathrm{e}}<250 \mathrm{keV}$. These conditions are easily satisfied in efther the profosed 
experiment, or in any reactor based on the HDZP concept, and the assumption of constant equilibrium between electrons and ions appears well-founded.

\section{A. Influence of the Heating Method on Confinement Configuration}

The heating current in the high density pinch also provides the equilibrium, which is grossly unstable to MHD medes as predicted by Suydam and Newicomb. 5,6 It is expected that these modes can be stabllized by gas-embeding for a time sufficient to achieve a batch burn. The investigation of the physics of the stabilization process should be a primary aim of any exploratory research.

\section{B. Physics of Heating Method}

The reactor concept relies unly on classical ohmic heating for sucress, and the physics of this method is well-established. Anomalous heating can come about in such devices, but, although beneficial, anomalous heating is not essential for a reactor.

Alpha particle heating may not be completely effective in such devices because the alpha gyroradius will be somewhat larger than the pinch radius for the assumed reactor parameters. The concept does not, however, require significant alpha energy deposition to reach high $Q$.

\section{Heating Energy and Power Requirement}

The minimum energy per unit length that must be supplied to heat the plasma in the absence of radiation is $W / \ell=2 \mathrm{~N}_{\ell} \mathrm{kT}-1.3 \mathrm{~kJ} / \mathrm{cm}$ for the required line densfty and temperature. In addition, radiation losses must be balanced during this phase. The radiated energy is $\mathrm{w}_{\mathrm{rad}}-5.4 \times 10^{-31} \mathrm{n}^{2} \mathrm{~T} / 2$ $\left(\pi r^{2} \ell\right) \tau J$. Ar estimate of the ohmic heating time can be worked out from Hammel's solution for the time required to reach the equilibrium pinch final temperature. ${ }^{*}$ This is $T_{\text {oh }} \sim 10^{15 / \mathrm{n}}$ seconds for the final temperature $\mathrm{T}=10 \mathrm{keV}$. With the equilibrium $11 \mathrm{ne}$ density $\mathrm{N}_{\ell} \sim 4 \times 10^{17} \mathrm{~cm}^{-1}$, this gives a radiation loss during heating of $w_{r a d}-700 \mathrm{~J} / \mathrm{sm}$, which is certainly an nverestimate because the final temperature was used. Ohmic heating must supply enough energy to make up for losses during the burn time. The

\footnotetext{
*This information was supplied by R. H. Lovberg, August 1979.
} 


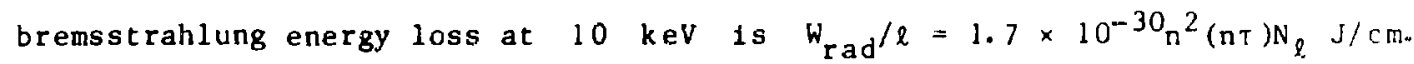
Again taking $n T-4 \times 10^{15}$ and $N_{\ell}-4 \times 10^{17} \mathrm{~cm}^{-1}$ gives a bremsstrahlung loss of $W_{o h} / \ell-2.7 \mathrm{~kJ} / \mathrm{cm}$, and the total heating energy needed including all of these requirements is $W_{\mathrm{oh}} / \ell-4.7 \mathrm{~kJ} / \mathrm{cm}$. Comparing this energy input requirement with the neutron energy output, $W_{n} / \ell-90 \mathrm{~kJ} / \mathrm{cm}$ (see Appendix), gives a simple $Q$ of about 19. Additional loss mechanisms (such as radial transport) w111 reduce this estimate of $Q$, and it is, therefore, important to determine the net energy deposition rate in such high-density pinches. This should be a prime objective of exploratory experiments.

The heating time is $\mathrm{T}_{\mathrm{OH}}-10^{15} / \mathrm{n} \mathrm{sec}$ for a final temperature of $10 \mathrm{keV}$. The high density reactors proposed by Hartman and Hammel have a density ot $\mathrm{n}>10^{21} \mathrm{~cm}^{-3}$, which would give heating times $\tau_{\mathrm{OH}}<10^{-6} \mathrm{sec}$, and a heatink power requirement of $\mathrm{P}_{\mathrm{oh}} / \ell>2 \mathrm{G} / \mathrm{cm}$ during the formation stage. The heating: power needed during the 4-us burn is much more modest: $P_{o h} / \ell-0.7 \mathrm{cW} / \mathrm{cm}$. If the first wall is at a radius of $5 \mathrm{~cm}$, then the radiation loading is $-22 \mathrm{MW} / \mathrm{cm}^{2}$ from bremsstrahlung, again emphasizing the need for a continuously renewable wall.

The power needed for heating is, of course, only a fraction of the tulat requirement. Much of the energy is stored in the magnetic field, and the amount can be estimated by assuming that the ratio of the pinch radius to that of the coaxial current return is $\sim 1: 500$. The inductance per unit length is then $\mathrm{L} / 2-13 \mathrm{nH} / \mathrm{cm}$, and the magnetic energy for the $1.1 \mathrm{MA}$ final current is $W_{B} / \ell-8 \mathrm{~kJ} / \mathrm{cm}$. The practical $Q$ of the reactor will bc affected by the efficiency of recovery of this energy, but even if none were recovered the $Q$ for this simple model would be no less than about 7 .

\section{Technological Requirements for Heat 1 ng}

The energy reguirements for a HDZP reactor are within the realm of present puised-power technology. Power supplies capable of delivering several Terrawatts have been constructed and used to deliver energy to systems for time scales ranging from a few tens of nanoseconds (eg. Blackjack) up to a few microseconds (eg. Scyllac).

The real limitation of present technology for this application may well be the ability to generate the required current waveform for the equilibrium HDZP. To malntain a true equilibrium from time zero would require an infinite rate of increase. This ideal cannot be achieved because of the finite 
Inductance of the pinch. One objective of exploratory experiments should be to study the transition between contraction and expansion phases of the pinch. From the results of such experiments much could be learned concerning the consequences of power supply "mis-match" for HDZP reactor systems.

\section{SIZE AND ECONOMICS}

\section{A. Beta, Q Range of Dutput Power}

The best answers to these questions must come from detailed reactor studies, of course. The nalve model used here only suggests that a HDZP reactor can operate at economical $Q$ values. It also appears that the power output can be easily adjusted by simple length scaling of the device. No external flelds are required for this concept, so the high-beta, high-field questions that arise in connection with other reactor concepts are somewhat 1rrelevant.

\section{B. Inherent Simplicity}

Inherent simplicity is one of the strongest points in favor of the HDLP fusion reactor concept.

- Geometrical simplicity requires reduced engineering effort.

- High density operation avolds vacuum and 1mpurity problems: no divertors are required.

- No external magnetic field colls are required.

- Ohmic heating requires no developmental effort: no high-technology heating is needed.

- Small plant size with low power output appears possible.

- Presently avallable pulse-power cechnology may prove sufficient for heating and confinement.

\section{v. TECHNOLOGICAL FACTORS}

As discussed above, there do not appear to be readily identifiable major technolngical problems relating to the power supply for an ohmically-heated HDZP reactor. If these exist, they will only become apparent when more is 
learned from the results of exploratory experiments and $t$ rom the results of detalled reactor systems studies.

The "critical path" for the HDZP reactor appears to be the technology of replacing the walls at a high enough repetition rate and low enough cost to make the reactor economical. Perhaps this can be accomplished in a continuous fashion with 11thium waterfalls or whirlpools such as those suggested for Inertial-confinement fusion concepts. Hartman, et al., have examined such renewable wall contalnment vessel concepts in thelr HDZP reactor study, ${ }^{2}$ and conclude that they are indeed a viable option.

\section{ANTICIPATED VALUE}

I belfeve that the value of the HDZP reactor lies in the possibility for 1 relatively inexpenstve and compact fusion power source with iittle need tur extrapolation of present technology. It 1s, of course, a high risk optinu because so little has been done experimentally to date, and as a consequente little is known about the physics of these devices. This only emphasizes the need for strong experimental prograus to explore the critical issues.

\section{SUMMARY}

The reactor concept based on the HDZP is, I believe, sufficiently credibl.. at this stage of understanding that physles experiments and reactor systems studies should be supported as soon as practicable.

A relatively small level of effort will greatly expand the physics knowledge of gas-embedded pinches, and yet should not have a great finanrial 1 mpact on other ongoing programs. 
APPENDIX

HDZP REACTOR MODEL

In this naive inodel $1 \mathrm{t}$ is assumed that the pinch remains in a state sufficlently close to equilibrium to enable the axial current to increase in time to the limiting Pease current, $I_{P}-1.1 \mathrm{MA}$, as described by Hammel. 1 50-50 mixture of DT is the fill gas, and a final burn temerature of $T$ - $10 \mathrm{keV}$ is assumed after reaching the limiting current. The pinch reactor is assuned to run as an un-1gnited power dinplifier for a burn time t after reaching the 1.l MA Pease current. The DT Lawson criterion at this temperature is $n T_{L}=10^{14} \mathrm{~s} / \mathrm{cm}^{3}$, and the Maxwellian DT reactivity is $\langle\sigma r\rangle-10^{-16} \mathrm{~cm}^{3} / \mathrm{s}$. The specification of the temperature and current fixes the plasma Line density, $N_{q}$. For the DT reactor temperacure, $T \sim 10 \mathrm{keV}$, thls is $N_{Q}-4 \times 10^{17} \mathrm{~cm}^{-1}$. Previous studies of HDZP reactors assume a plasma density $\mathrm{n}>10^{21} \mathrm{~cm}^{-3}$. When required, the estimates given here use $\mathrm{n}=10^{21} \mathrm{~cm}^{-3}$, which corresponds to a ptnch radius, $r$, of $1.1 \times 10^{-2} \mathrm{cr}$. Note that the Lawson $t$ ime, ${ }^{2} \mathrm{~L}-10^{\mathrm{i} 4} / \mathrm{n}$, for this density is only $0.1 \mathrm{us.}$

The neutron energy output is $E_{n}=1 / 4 n^{2}\langle\sigma v\rangle\left(\pi r^{2} \ell\right) T \times 14$ Mev, and thus

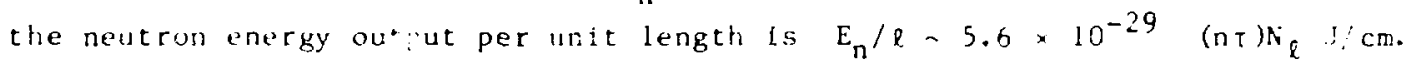
The fraction of fuel burned in cime $T$ is estimated to be $f-1 / 2$ <ov $(n \tau)-5 \times 10^{-17}(n \tau)$. Thus, for a burnup of $20 \%$ ot the fuel, $n T \sim 4 \times 20^{15}$, which gives a burr time of about 40 lawson times, and a thermonuclear neutron output $E_{n} / 8-90 \mathrm{~kJ} / \mathrm{cm}$. With a first wall at $5 \mathrm{~cm}$, this would ies.lt in a neutron loading of $-700: 1 \mathrm{~W} / \mathrm{cm}^{2}$, which would necessitate renewal of the first wall after each burn cycle, perhaps by using a flowing-lithium blast-contalnment vessel as suggested by Hartman. 2

Thus, assuming a $30 \%$ thermal recovery efficlency from the flowlng lithium, a $1 \mathrm{MW}$ reactor would require a length $\ell$ - $370 \mathrm{~cm}$ if the repetition rate were one burn cycle each 10 seconds. 
1. J. E. Hammel, Los Al amos Sclent if ic laboratory report LA-6203-MS (1976).

2. C. W. Ha!tman, G. Carlson, M. Hoffman, R. Werner, and D. Y. Cheng, Nucl. Fuston 17, 909 (1977).

3. R. L. Hagenson, A. S. Ta1, R. A. Krakowskl, and R. W. Moses, Los Alamos Sclentific laboratory report l.A-8186-MS (1980).

4. S. G. Al ikhanov, I. K. Konkashbeav, and P. 2. Chebotaev, Nuci. Fusion 10, $13(1970)$.

5. B. R. Suydam, Proc. Second U. N. Conf. on Peaceful Uses of Atomir Entergy, 31, 157 (1958).

6. W. A. Newcomb, Ann. Phys. 10, 232 (1960). 